\title{
Grape Seed Extract Given Three Hours After Injury Suppresses Lipid Peroxidation and Reduces Hypoxic-Ischemic Brain Injury in Neonatal Rats
}

\author{
YANGZHENG FENG, YI-MING LIU, MICHAEL H. LEBLANC, ABHAY J. BHATT, AND PHILIP G. RHODES \\ Department of Pediatrics [Y.F., M.H.L., A.J.B., P.G.R.], University of Mississippi Medical Center, Jackson, Mississippi 39216; \\ Department of Chemistry [Y.M.L.], Jackson State University, Jackson, Mississippi 39217
}

\begin{abstract}
We have reported that pretreatment with grape seed extract (GSE), a potent antioxidant, is neuroprotective. This study examined whether treatment after injury with GSE is protective. Seven-day-old rat pups had the right carotid artery ligated, and then $2.5 \mathrm{~h}$ of $8 \%$ oxygen. GSE $(50 \mathrm{mg} / \mathrm{kg})$ or vehicle was administered by i.p. initial injection at $5 \mathrm{~min}$ to $5 \mathrm{~h}$ after reoxygenation, with an additional three doses within $26 \mathrm{~h}$ after injury. Brain damage was evaluated by weight deficit of the right hemisphere at $22 \mathrm{~d}$ after hypoxia. Treatment at $3 \mathrm{~h}$ after reoxygenation reduced brain weight loss from $21.0 \pm 3.3 \%$ in vehicle-treated pups $(n=31)$ to $11.4 \pm$ $2.8 \%$ in treated pups $(n=31, p<0.05)$. GSE lowered body temperature, but reduced brain injury even when body temperature was controlled. GSE reduced neurofunctional abnormalities caused by the hypoxia-ischemia (HI). GSE reduced a $\mathrm{HI}$ induced increase in 8-isoprostaglandin $\mathrm{F}_{2 \alpha}\left(8\right.$-isoPGF $\left.\mathrm{PG}_{2 \alpha}\right)$ and reduced an HI-induced increase in the proapoptotic protein c-jun in the brain cortex. GSE up to $3 \mathrm{~h}$ after reoxygenation reduces brain injury in rat pups, probably by suppressing lipid peroxidation and the proapoptotic protein c-jun. (Pediatr Res 61: 295-300, 2007)
\end{abstract}

$\mathrm{O}$ xygen and nitrogen free radicals are thought to play a crucial role in HI brain injury (1). Free radical production has been detected in the brain during cerebral ischemia. Levels of free radicals increase significantly with reperfusion (2). Agents known to scavenge or enzymatically degrade free radicals have frequently been shown to be neuroprotective in HI brain injury (3).

GSE contains a number of polyphenols including procyanidins and proanthocyanodins monomers and polymers and their gallates (4). GSE has been reported to have many pharmacologic mechanisms of action including antioxidant properties and reduced apoptotic cell death (5-10). GSE protects heart function and reduces infarct size in experimental cardiac ischemia (11). GSE also reduces brain injury in the adult gerbil forebrain ischemia model (12) and attenuates renal damage in the rat renal ischemia reperfusion model (13). We have reported that pretreatment with GSE reduced brain

Received April 28, 2006; accepted October 24, 2006.

Correspondence: Yangzheng Feng, M.D., Department of Pediatrics, University of Mississippi Medical Center, 2500 North State Street, Jackson, MS 39216; e-mail: yfeng@ped.umsmed.edu

Statement of financial support: No extramural financial support was received in support of this study. None of the authors have a financial interest in the outcome of the study.

DOI: $10.1203 / p d r .0 b 013 e 318030 c 92 d$ injury in newborn rats and reduced a hypoxia-induced increase in brain lipid peroxidation (14). Because protection against brain damage is crucially time sensitive, understanding the window of time when treatment with GSE is effective will be important in deciding whether clinical trials are feasible.

HI brain injury is an important cause of death and disability in human newborns. The neonatal rat HI model (15) has been well characterized and extensively used to assess synthetic neuroprotective agents (16).

This study examined whether treatment after injury with GSE protects against brain injury and how long after reoxygenation treatment is still effective. This study also examined whether treatment after injury with GSE could reduce the formation of oxygen and nitrogen free radicals, as measured by 8 -isoPGF ${ }_{2 \alpha}$ and reduce levels of the proapoptotic protein c-jun in the HI rat pups model.

\section{MATERIALS AND METHODS}

\begin{abstract}
Animal protocol. This protocol was approved by our institutional committee on animal use. Rats were cared for in accordance with National Institutes of Health guidelines. The neonatal rat HI procedure was performed as described by Rice et al. (15). Seven-day-old Sprague-Dawley rat pups of either sex, weighing between 12 and $16 \mathrm{~g}$ (Harlan Sprague Dawley, Indianapolis, IN) were anesthetized with isoflurane. The right common carotid artery was exposed, isolated, and permanently doubly ligated. After surgery, the rat pups were returned to their dams for 2- to 3-h recovery. Hypoxic exposure was achieved by placing the rat pups in $1.5-\mathrm{L}$ sealed jars immersed $5.5 \mathrm{~cm}$ deep in a $37^{\circ} \mathrm{C}$ water bath and subjected to a warmed, humidified mixture of $8 \%$ oxygen $/ 92 \%$ nitrogen bubbled through $37^{\circ} \mathrm{C}$ water and delivered at $4 \mathrm{~L} / \mathrm{min}$ for $2.5 \mathrm{~h}$. After this hypoxic exposure, the pups were returned to their dams and some pups were taken for 8 -isoPGF $2 \alpha$ and c-jun assay, and other pups were allowed to recover and grow for $22 \mathrm{~d}$ for measuring brain injury.
\end{abstract}

Drug treatment. Pups from each litter were randomly assigned and marked for treatment with GSE or vehicle. GSE, a brown-red powder (purity: 96\%), was prepared in-house using a previously described protocol (14). GSE in doses of $50 \mathrm{mg} / \mathrm{kg}$ was dissolved in $10 \mu \mathrm{L}$ of saline per gram of body weight and administered by i.p. injection at $5 \mathrm{~min}$ and 1,3 , or $5 \mathrm{~h}$ after reoxygenation. GSE in doses of $25 \mathrm{mg} / \mathrm{kg}$ was administered at $5 \mathrm{~min}$ after reoxygenation. The pups given their initial injection at $5 \mathrm{~min}$ or $1 \mathrm{~h}$ after reoxygenation received a second dose at $4 \mathrm{~h}$ after reoxygenation. The pups given their initial injection at 3 and $5 \mathrm{~h}$ after reoxygenation received a second dose at approximately 12 and $14 \mathrm{~h}$ after reoxygenation, respectively. All four groups of pups received third and fourth doses of GSE at approximately 18 and $26 \mathrm{~h}$ after reoxygenation, respectively. The vehicle-treated groups were given $10 \mu \mathrm{L}$ of saline per gram of body weight. These doses were chosen from previous studies (14).

Abbreviations: GSE, grape seed extract; HI, hypoxia-ischemia, hypoxicischemic; 8-isoPGF $\mathbf{2}_{\mathbf{\alpha}}$, 8-isoprostaglandin $\mathrm{F}_{2 \alpha}$ 
A
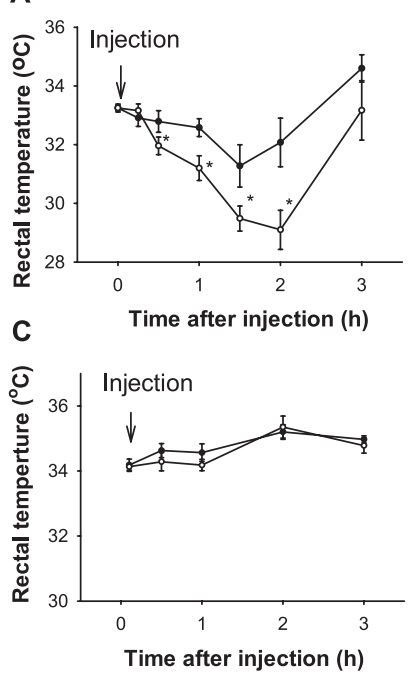

B
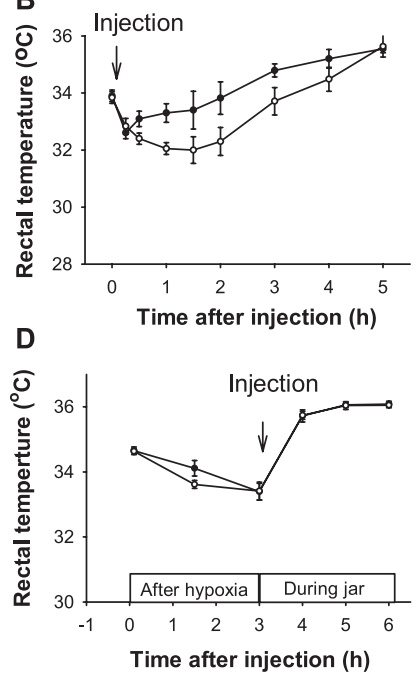

Figure 1. Effect of treatment with GSE (open circles) and vehicle (filled circles) at $5 \mathrm{~min}$ after hypoxia on rectal temperature. The error bars are SEM. Rectal temperatures obtained for the first $2 \mathrm{~h}$ after treatment were significantly lower in the $50 \mathrm{mg} / \mathrm{kg}$ of GSE-treated group $(n=7)$ than in the vehicletreated pups $(n=6),{ }^{*} p<0.05, * * p<0.01 v s$ vehicle $(A)$, but the group treated with $25 \mathrm{mg} / \mathrm{kg}$ showed no significant decrease $(n=8$ in each, $p>$ $0.05, B)$. Leaving the pups in the warm jars for $3 \mathrm{~h}$ after treatment with 50 $\mathrm{mg} / \mathrm{kg}$ of GSE $(n=6)$ or vehicle $(n=6)$ eliminates the difference in rectal temperature between the groups $(p>0.05, C)$. (D) Effect of treatment with 50 $\mathrm{mg} / \mathrm{kg}$ of GSE at $3 \mathrm{~h}$ after hypoxia on rectal temperature. Pups were left in the warm jars for $6 \mathrm{~h}$ after treatment. There were no significant differences in the temperature between the GSE-treated group $(n=7)$, and the vehicle-treated group $(n=6, p>0.05)$.

Measurement of rectal temperature. To evaluate whether neuroprotection by GSE was dependent on systemic hypothermia, rectal temperature was measured with a 36-gauge flexible thermocouple (Omega Engineering Inc., Stamford, CT). This was first done in a subset of pups before i.p. injection (25 or $50 \mathrm{mg} / \mathrm{kg}$ of GSE at $5 \mathrm{~min}$ after hypoxia, six to eight pups in each group) and at $0.5,1,1.5,2,3$, and $5 \mathrm{~h}$ after injection. Treatment with $50 \mathrm{mg} / \mathrm{kg}$ of GSE $5 \mathrm{~min}$ after reoxygenation significantly decreased rectal temperatures at $0.5,1,1.5$, and $2 \mathrm{~h}$ after treatment relative to the vehicle-treated group (Fig. $1 A$ ), but the group treated with $25 \mathrm{mg} / \mathrm{kg}$ showed no significant decrease (Fig. $1 B$ ). From the experiments that had already been done, the $5 \mathrm{~min}$ and the $3 \mathrm{~h}$ after reoxygenation experiments were then repeated, now keeping the pups in the warm jars from reoxygenation for $3 \mathrm{~h}$ after injection of $50 \mathrm{mg} / \mathrm{kg}$ of GSE or vehicle. These are the warm jars used for hypoxia ( $8 \%$ oxygen) described in detail previously, but are now used with $21 \%$ oxygen. Keeping the pups in this warm humid environment eliminated the temperature difference between the groups. This is true for both the $5 \mathrm{~min}$ after reoxygenation experiment (Fig. $1 C$ ) and the $3 \mathrm{~h}$ after reoxygenation experiment (Fig. 1D). Normal rat pups not subjected to HI, but treated with $50 \mathrm{mg} / \mathrm{kg}$ of GSE or vehicle had decreases in temperature in response to GSE relative to the vehicle-treated group if both groups were kept away from the dam and the nest of siblings (data not shown). In addition, we measured rectal temperature in a subset of the pups after the second, third, and fourth doses of GSE or vehicle (data not shown). If these measurements were made in a $25^{\circ} \mathrm{C}$ room 15 min after removing the pup from the nest, as is our usual procedure, we found that the GSE-treated pups were significantly cooler than the vehicle-treated pups. In a slight deviation from our usual procedure, we measured the temperature immediately after removing the pup from the nest rather than 15 min later to better match the temperatures in the brain weight experiments and to capture the added warmth of the nest. This eliminated any significant differences between the GSE- and vehicle-treated groups (group or group with time differences) for the second, third, and fourth doses. This was not an adequate response for the first dose because the rat pups for the first $1-2 \mathrm{~h}$ after the hypoxic period are lethargic and do not seek the warmth of the nest by movement and vocalization as a normal rat pup of this age would do. Rat pups of this age cool rapidly once they are removed from the nest and the dam (17). Rectal temperature and brain temperatures are almost identical even when tested during $\mathrm{HI}$ in 7-d-old rats using this same protocol (18). Because

decreased body temperature both during and after the hypoxia can affect the outcome, it is essential that both the treated and control animals maintain similar temperatures $(18,19)$.

Neurofunctional assessment: foot fault test. The foot fault test was performed $21 \mathrm{~d}$ after brain injury according to a published method (20). Using the previously described neonatal $\mathrm{HI}$ and treatment procedures, the experimental groups treated with $25 \mathrm{mg} / \mathrm{kg}$ of GSE at $5 \mathrm{~min}$ after reoxygenation and with $50 \mathrm{mg} / \mathrm{kg}$ of GSE at $3 \mathrm{~h}$ after reoxygenation with temperature control, both during and after hypoxia, were used. Rats were placed on an elevated stainless steel grid $30 \times 30 \mathrm{~cm}, 1 \mathrm{~m}$ above the floor with $3 \mathrm{~cm}^{2}$ holes and a wire diameter of $0.4 \mathrm{~cm}$. Each pup was placed on the grid and observed for 2 min. Occasionally a foot would be misplaced while walking over the grid and slip through a grid opening (foot fault). The excess of left, contralateral foot faults, to right, ipsilateral foot faults, was recorded (20).

Gross brain damage grading. Rat pups were anesthetized with pentobarbital and decapitated $22 \mathrm{~d}$ after hypoxic exposure. Brains were scored normal, mild, moderate, or severe by the method of Palmer et al. (21) by a blinded observer. Normal (0) is no reduction in the size of the right hemisphere, mild (1) is visible reduction in right hemisphere size, moderate (2) is large reduction in hemisphere size from a visible infarct in the right parietal area, and severe (3) is nearly total destruction of the hemisphere. After removing the cerebellum and brainstem, the brain was divided into two hemispheres and weighed. Results are presented as the percentage of loss of hemispheric weight of the right side relative to the left [(left-right)/left $\times 100]$. This HI model results in brain damage only on the ipsilateral side (21). The loss of hemispheric weight can be used as a measure of brain damage in this model because enough time elapsed to allow resorption of edema and dead tissue (22,23).

Measurement of.8-isoPGF ${ }_{2 \alpha}$ A second set of experiments was performed to determine the effect of GSE on 8 -isoPGF $2 \alpha .8$-isoPGF $2 \alpha$ was measured in rat pups treated with GSE $(n=6)$ or with vehicle $(n=6)$. Using the previously described neonatal HI procedure, the rat pups were treated with 50 $\mathrm{mg} / \mathrm{kg}$ of GSE by i.p. injection at $5 \mathrm{~min}$ after hypoxia, with a second dose given $4 \mathrm{~h}$ after reoxygenation. In the experimental brain injury model, the peak activation of 8 -isoPGF $2 \alpha$ occurs at $24 \mathrm{~h}$ after the brain injury (24). Therefore, pups were anesthetized with $50 \mathrm{mg} / \mathrm{kg}$ pentobarbital at $24 \mathrm{~h}$ after hypoxia. The cortex in both lesioned and unlesioned hemispheres was separately dissected and frozen at $-80^{\circ} \mathrm{C} .8$-isoPGF ${ }_{2 \alpha}$ was assessed as described by Hoffman et al. (24) and our previous studies (14). The concentrations of 8 -iso- $\mathrm{PGF}_{2 \alpha}$ were determined colorimetrically with a microplate reader at 405 $\mathrm{nm}$. The estimated amount of $8-\mathrm{isoPGF}_{2 \alpha}$ in the tissue was then calculated as $\mathrm{pg} / \mathrm{g}$ brain tissue.

Western blot analysis for c-jun. A third set of experiments was performed to determine the effect of GSE on c-jun protein. C-jun protein was measured in rat pups treated with GSE or vehicle 5 min after hypoxia (12 in each group). Using the above-described neonatal HI procedure, the rat pups were treated with $50 \mathrm{mg} / \mathrm{kg}$ of GSE by i.p. injection at $5 \mathrm{~min}$ after hypoxia, with a second dose given $4 \mathrm{~h}$ after reoxygenation. At $24 \mathrm{~h}$ after reoxygenation, the pups were decapitated, brains were removed, cortexes in both lesioned and unlesioned hemispheres were separately dissected and were frozen at $-80^{\circ} \mathrm{C}$. C-jun protein was assessed as described by Sato et al. (10). Samples with $60 \mu \mathrm{g}$ of protein were denatured and separated electrophoretically against molecular weight controls and transferred to a polyvinylidene difluoride membrane. After incubation in 5\% nonfat milk, the membranes were washed and incubated with 1:1000 diluted primary rabbit antibodies specifically against c-jun (Santa Cruz Biotech, Santa Cruz, CA) for 2 h, and then with 1:3000 diluted secondary antibodies of horseradish peroxidase-conjugated to antirabbit IgG (Santa Cruz Biotech) for $1 \mathrm{~h}$ at room temperature. The membranes were washed, then incubated in Amersham's ECL Western blotting detection reagents, and exposed to ECL Hyperfilm (Amersham). Films were scanned using a Logitech Scanman densitometer (Logitech, Inc., Freemont, CA). Each gel contained vehicle- and GSE- treated pups. Separate assays were done on each pup.

Statistical analysis. Categorical variables were analyzed with the $\chi^{2}$ test. Continuous variables are expressed as mean \pm SEM and the statistical significance of differences between groups was determined using analysis of variance with the Newman-Keuls test. Differences were considered significant at $p \leq 0.05$. The size of the groups was chosen to provide an $80 \%$ chance of detecting a decrease in the percentage of loss of the right brain weight of $1 / 3$ at the 0.05 level.

\section{RESULTS}

Brain weight deficit. Figure 2 shows the weight deficit in the right hemisphere relative to the left hemisphere. In the groups treated with $50 \mathrm{mg} / \mathrm{kg}$ of GSE, the group treated at 5 


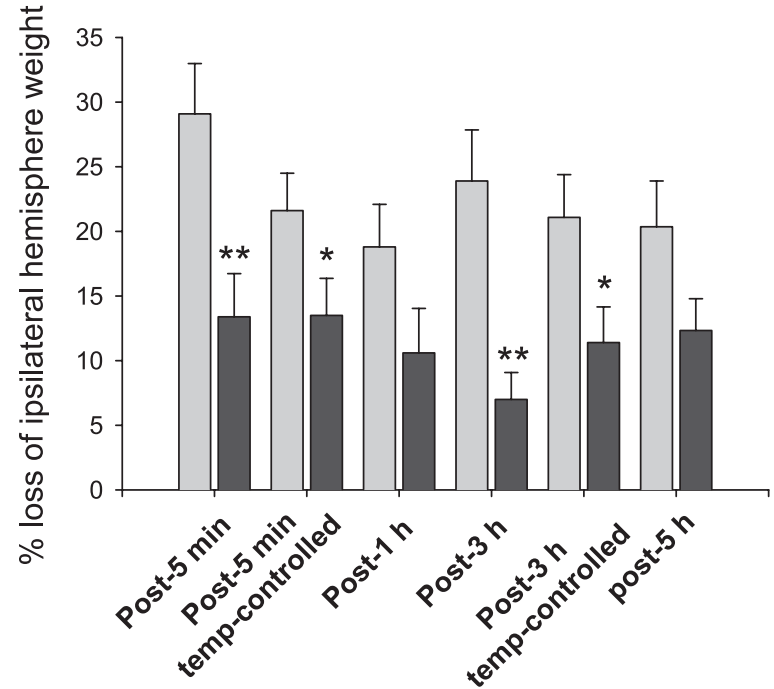

Figure 2. The percentage of reduction in right cerebral hemisphere weight measured using the left hemisphere weight as standard. GSE $(50 \mathrm{mg} / \mathrm{kg}$, solid columns) or vehicle (shaded columns) was initially administered at $5 \mathrm{~min}, 1 \mathrm{~h}$, $3 \mathrm{~h}$, or $5 \mathrm{~h}$ after reoxygenation with additional doses of GSE as described in Methods. Data are presented as mean \pm SEM. The animal numbers are as described in Results. Treatment with $50 \mathrm{mg} / \mathrm{kg}$ of GSE with an initial dose at $5 \mathrm{~min}$ or $3 \mathrm{~h}$ after reoxygenation, whether temperature controlled after injury or not, significantly decreased the percentage of reduction in right hemisphere weight compared with vehicle $(* p<0.05, * * p<0.01 v s$ vehicle). There was a trend toward a reduction in right hemisphere weight in the groups treated at $1 \mathrm{~h}(p=0.09)$ and $5 \mathrm{~h}(p=0.06)$ after reoxygenation, but it did not reach statistical significance.

min after reoxygenation where the GSE-treated group was allowed to be colder than the vehicle-treated group, the right hemisphere weight deficit was significantly greater in the vehicle-treated group $(29 \pm 4 \%, n=30)$ than in the GSEtreated group (13 $\pm 3 \%, n=24, p<0.01$ versus vehicle). The weight deficit in the right hemisphere in the group treated 5 min after reoxygenation where the temperature was main- tained in the GSE-treated group was significantly greater in the vehicle-treated group $(22 \pm 3 \%, n=36)$ than in the GSE-treated group $(14 \pm 3 \%, n=32, p<0.05$ versus vehicle). The weight deficit in the right hemisphere in the group treated $1 \mathrm{~h}$ after reoxygenation was greater in the vehicle-treated group $(19 \pm 3 \%, n=30)$ than in the GSEtreated group, but the result was not statistically significant (11 $\pm 3 \%, n=28, p=0.09$ versus vehicle). In the group treated $3 \mathrm{~h}$ after reoxygenation where the GSE-treated group's temperature was allowed to fall below that in the vehicletreated group, the weight deficit in the right hemisphere was greater in the vehicle-treated group $(24 \pm 4 \%, n=20)$ than in the GSE-treated group $(7 \pm 2 \%, n=19, p<0.01$, versus vehicle). In the group treated $3 \mathrm{~h}$ after reoxygenation where the GSE-treated group's temperature was not allowed to fall below that in the vehicle-treated group, the weight deficit in the right hemisphere was greater in the vehicle-treated group $(21 \pm 3 \%, n=31)$ than in the GSE-treated group $(11 \pm 3 \%$, $n=31, p<0.05$, versus vehicle). The weight deficit in the right hemisphere in the group treated $5 \mathrm{~h}$ after reoxygenation was greater but only borderline significantly greater in the vehicle-treated group $(20 \pm 4 \%, n=19)$ than in the GSEtreated group (12 $\pm 2 \%, n=22, p=0.06$, versus vehicle).

In the group treated with $25 \mathrm{mg} / \mathrm{kg}$ of GSE at $5 \mathrm{~min}$ after reoxygenation, the right hemisphere weight deficit was $29 \pm$ $3 \%$ in the vehicle-treated group $(n=23)$, and $22 \pm 3 \%$ in the GSE-treated group $(n=23)$, respectively. This was not statistically significant $(p=0.14)$.

Gross brain injury. Gross neurologic damage score was determined by an observer blind to the drug treatment of the rat pups (Table 1). For the rat pups treated $5 \mathrm{~min}$ and $3 \mathrm{~h}$ after reoxygenation, where temperature was controlled during the injury but not after injury, neurologic score was higher in the vehicle-treated group than in the GSE-treated group $(p<$ 0.01). For rat pups treated 5 min and $3 \mathrm{~h}$ after reoxygenation,

Table 1. Gross damage score

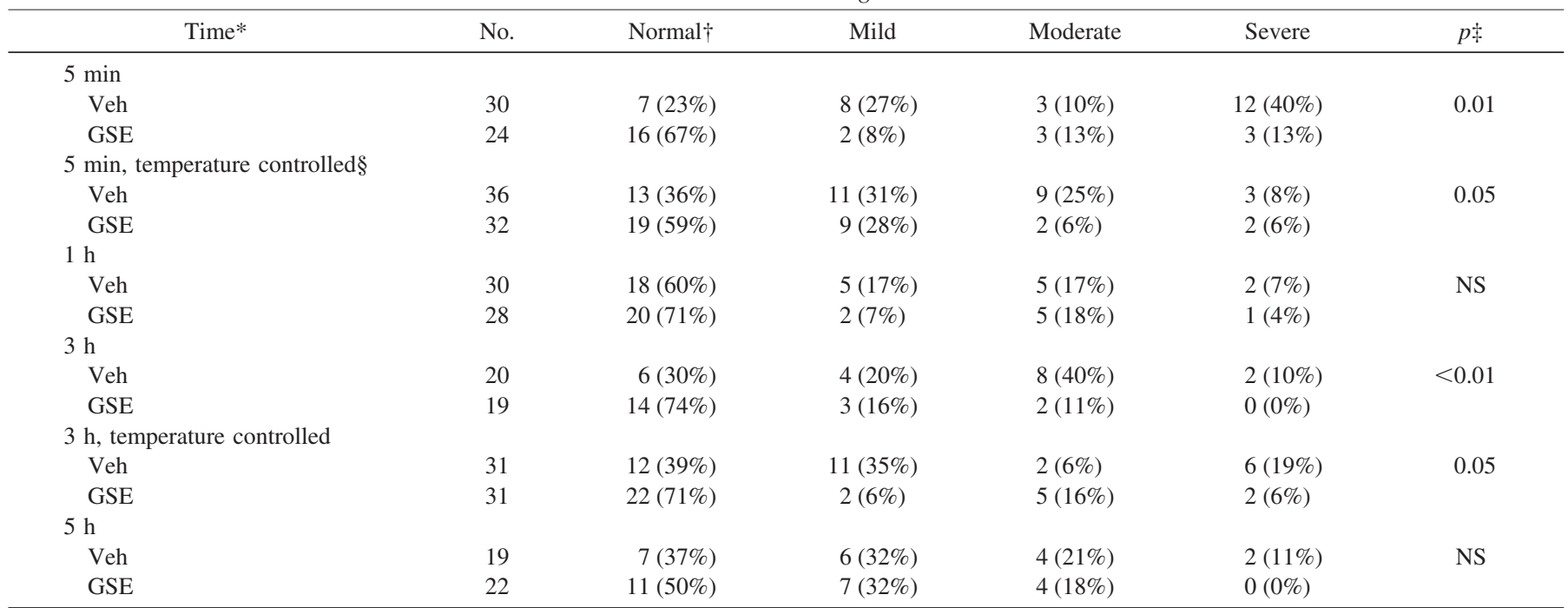

* The time after reoxygenation when the first dose of GSE or vehicle (Veh) was given.

$\dagger$ The number $(\%)$ of pups receiving the designated gross damage score by a blinded observer.

$\ddagger p$ value, GSE $v s$ vehicle.

$\S$ Temperature controlled not only during injury but also from reoxygenation to $3 \mathrm{~h}$ after the first injection of GSE or vehicle. 


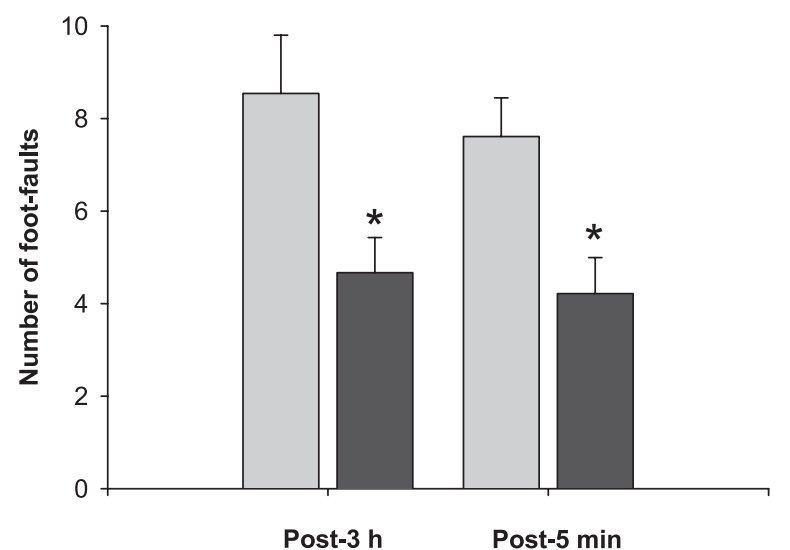

Figure 3. The effect of GSE on the foot fault test. Treatment with $50 \mathrm{mg} / \mathrm{kg}$ of GSE with an initial dose at $3 \mathrm{~h}$ after reoxygenation $\square$ and treatment with $25 \mathrm{mg} / \mathrm{kg}$ of GSE with an initial dose at $5 \mathrm{~min}$ after reoxygenation $\mathbf{a d}$ significantly fewer foot faults than the vehicle-treated groups, $n=23-24$ in each group, ${ }^{*} p<0.05$.

where temperature was controlled after injury, the neurologic injury score was also higher in the vehicle-treated group relative to the GSE-treated group ( $p=0.05)$. Gross neurologic damage in the group treated 1 or $5 \mathrm{~h}$ after reoxygenation was greater in the vehicle-treated group than in the GSE-treated group, but these results were not statistically significant. Gross neurologic damage score was not statistically significant in the group treated with $25 \mathrm{mg} / \mathrm{kg}$ of GSE at $5 \mathrm{~min}$ after hypoxia and in the vehicle-treated group ( $p>0.05$, data not shown).

Neurofunctional test. In pups treated with $50 \mathrm{mg} / \mathrm{kg}$ of GSE or vehicle at $3 \mathrm{~h}$ after reoxygenation with temperature control groups, the number of foot faults per pup was $8.5 \pm$ $1.3(n=24)$ in the vehicle-treated group and $4.7 \pm 0.8(n=$ $24, p<0.05)$ in the GSE-treated group. In pups treated with $25 \mathrm{mg} / \mathrm{kg}$ of GSE or vehicle at $5 \mathrm{~min}$ after reoxygenation, the number of foot faults per pup was $7.6 \pm 0.8(n=23)$ in the vehicle-treated group and $4.2 \pm 0.8(n=23, p<0.05)$ in the GSE-treated group. The GSE-treated groups had better neurologic function on this test than the vehicle-treated groups (Fig. 3).

$\boldsymbol{8}$-isoPGF $\boldsymbol{F}_{\boldsymbol{\alpha} \boldsymbol{\alpha}}$ 8-isoPGF ${ }_{2 \alpha}$ was measured in pups treated with $50 \mathrm{mg} / \mathrm{kg}$ GSE or vehicle at $5 \mathrm{~min}$ after reoxygenation. 8 -isoPGF $2 \alpha$ was $91 \pm 7 \mathrm{pg} / \mathrm{g}(n=6)$ in the GSE-treated group, and $263 \pm 72 \mathrm{pg} / \mathrm{g}(n=6)$ in the vehicle-treated group $(p<0.05)$. The increase in 8 -isoPGF ${ }_{2 \alpha}$ caused by $\mathrm{HI}$ injury was substantially reduced by treatment with GSE (Fig. 4).

$c$-jun. c-jun was measured in pups treated with GSE 5 min after reoxygenation. c-jun was expressed as a percentage of increase in optical density (OD) of the ipsilateral hemisphere relative to the contralateral hemisphere. c-jun was $56 \pm 11 \%$ in the vehicle-treated group $(n=12)$, and $30 \pm 1 \%$ in the GSE-treated group $(n=12, p<0.05)$. The increase in c-jun caused by the $\mathrm{HI}$ injury was substantially reduced by treatment with GSE (Fig. 5).

\section{DISCUSSION}

GSE reduces brain injury even when given $3 \mathrm{~h}$ after injury. This has been demonstrated by the reduction in the loss of

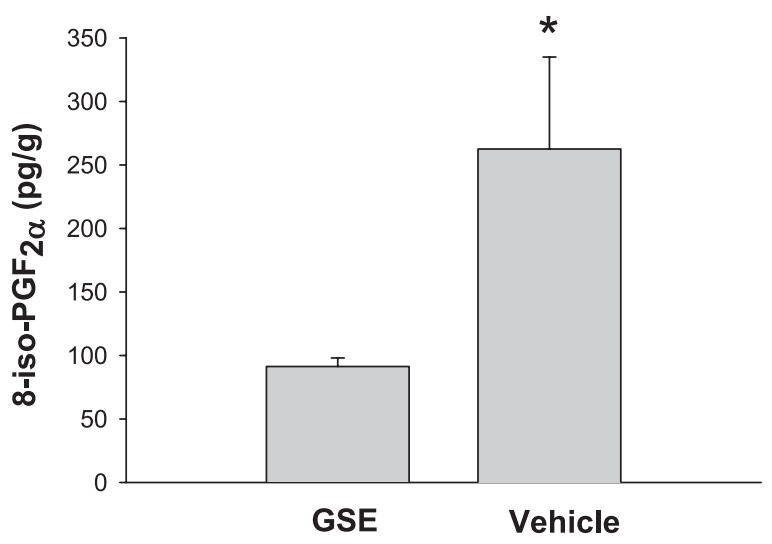

Figure 4. The effect of GSE on brain 8 -isoPGF ${ }_{2 \alpha}$. The concentrations of 8 -isoPGF $2 \alpha$ in the cortex of the right hemisphere in the GSE-treated group $(n=$ 6) were significantly lower than in the vehicle-treated group $(n=6) .{ }^{*} p<0.05$.
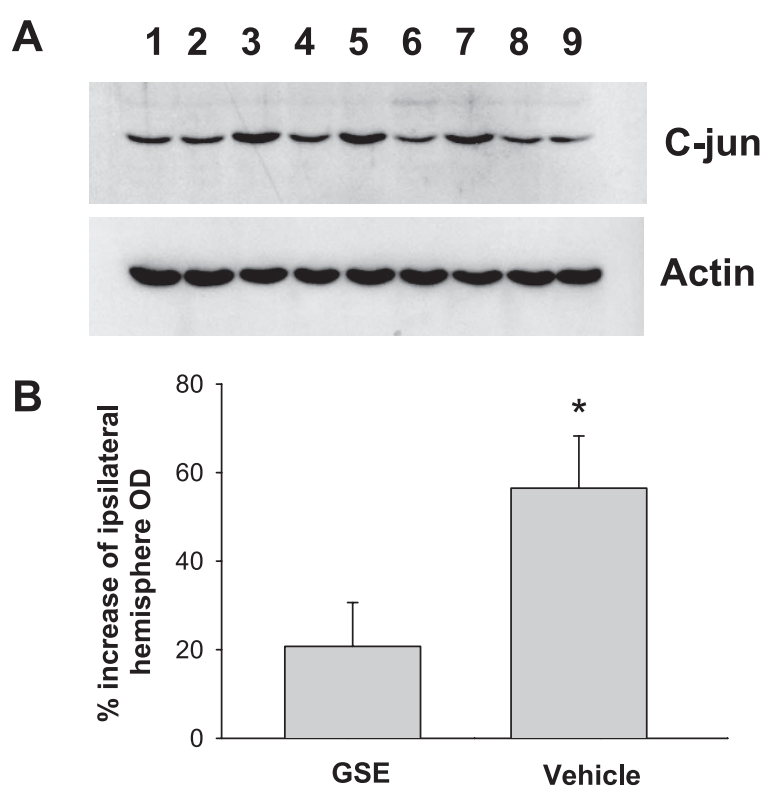

Figure 5. Effect of GSE on c-jun concentration. The phosphorylated c-jun was detected by Western blotting with the use of specific antibodies as described in the Methods section. (A) Representative Western blot for c-jun and actin. Lane 1, sham right hemisphere; lanes 2 and 4, vehicle left hemisphere; lanes 3 and 5, vehicle right hemisphere; lanes 6 and 8, GSE left hemisphere; lanes 7 and 9, GSE right hemisphere. $(B)$ c-jun was expressed as a percentage of increase in OD of the ipsilateral hemisphere relative to the contralateral hemisphere. The concentrations of c-jun in the cortex of the right hemisphere in the GSE-treated group $(n=12)$ were significantly lower than in the vehicle-treated group $(n=12) * p<0.05$.

brain weight on the ipsilateral side relative to the contralateral side. Because brain weighs approximately $1 \mathrm{~g} / \mathrm{mL}$, weight loss is equivalent to volume loss. McDonald and coworkers (23) have shown that the extent of unilateral reduction in hemisphere weight is highly correlated with cellular damage. By delaying assessment until $22 \mathrm{~d}$ after injury, we included very late cell death, which can make early measurement hard to interpret (25). The foot fault test is a sensorimotor test that could be used for long-term evaluation of functional deficits after HI in rats (20). Our data have also shown that brain function was better in the GSE-treated groups than in the vehicle-treated groups. Histopathologic measurement showing 
significantly greater loss of nerve cells in the cortex, hippocampus, and thalamus of the vehicle-treated pups relative to the GSE-treated pups has been previously reported (14). In addition, we demonstrated neuroprotection using the gross anatomic method of Palmer et al. (21), scored by a blinded observer. The therapeutic window for GSE was up to $3 \mathrm{~h}$ after hypoxia in either temperature uncontrolled or controlled pups. However, it is unclear why the group receiving post $1 \mathrm{~h}$ treatment with GSE had no significant protection.

Rectal temperature was lowered by GSE in rat pups by approximately $2^{\circ} \mathrm{C}$ for $2 \mathrm{~h}$. This was only seen in a cold environment and thus was not apparent in our pretreatment paper where the $2.5 \mathrm{~h}$ immediately after dosing were spent in the warm, humid jars in $8 \%$ oxygen (14). When a group treated after reoxygenation was kept warm, from reoxygenation through the first $3 \mathrm{~h}$ after dosing, the difference in temperature between the groups was eliminated. Based on the work of Yager and coworkers using a similar $7 \mathrm{~d}$ old rat $\mathrm{HI}$ model, we would not expect a drop in temperature of $2^{\circ} \mathrm{C}$ for $2 \mathrm{~h}$, beginning after injury to be an effective neuroprotectant (18).

The reduction in brain injury by GSE was associated with a reduction in the increase in lipid peroxidation caused by $\mathrm{HI}$ as measured by 8 -iso- $\mathrm{PGF}_{2 \alpha}$, a sensitive and specific technique for measuring oxygen radicals $(24,26) . \mathrm{F}_{2}$-isoprostanes are nonenzymatic products of the oxygen radical-induced lipid peroxidation of arachidonic acid. They are relatively stable once formed. $\mathrm{F}_{2}$-isoprostanes are formed initially as esterified fatty acids attached to phospholipids and then are released to their free form by the action of phospholipases, thus delaying the elevation of levels in the tissues (26).

GSE are powerful antioxidants in aqueous systems (5-9). They have greater antioxidant activity than vitamin $\mathrm{E}$ or vitamin $\mathrm{C}$ on a weight/volume basis $(5,6)$. Procyanidins, a component of GSE, has the highest stoichiometric factors among known natural antioxidants (6). GSE scavenges superoxide and peroxyl radicals, quenches singlet oxygen, and chelates iron (6). Because different compounds are preferentially involved in each of these activities, it may be difficult to retain the activity while purifying the product.

GSE can block cell death signaling mediated through the proapoptotic transcription factors and genes such as c-jun $(10,27)$. Apoptosis is an energy-requiring process and needs de novo proapoptotic gene expression. Apoptosis process is associated with the induction of the expression of a number of pro- as well as antiapoptotic transcription factors and genes. During ischemia/reperfusion, c-jun functions as a proapoptotic factor regulating apoptosis (10). We saw a decrease in the level of the protein c-jun in the GSE-treated group. This is consistent with the hypothesis that GSE's neuroprotective effects are caused by a combination of free radical inhibition and antiapoptotic effects, with the antiapoptotic effects mediated through c-jun. Long-term treatment with GSE increases expression of bcl-xl and prevents ladder-like DNA fragmentation (28). The antiapoptotic actions of GSE are probably downstream from and thus could be secondary to GSE's radical scavenging (29). Apoptosis is a natural process that functions in development to mold the central nervous system. After birth, apoptosis is thought to eliminate damaged cells and remove their remains without causing inflammation. Thus, it is significant to see from our study not only a smaller volume of brain injury in the GSE-treated pups, but also better brain function after injury in the GSE-treated pups.

In conclusion, our findings indicate that GSE up to $3 \mathrm{~h}$ after reoxygenation reduces brain injury in rat pups, probably by suppressing lipid peroxidation and the proapoptotic protein c-jun. The results also support that GSE is a novel, reasonably safe, and potentially cost-effective therapeutic agent for the treatment of brain injury $(5,7,8,13,14)$. The fact that GSE in a cold environment induces hypothermia could be an advantage because postinjury hypothermia has been shown to reduce HI brain injury in human neonates (30), and agents that act synergistically with hypothermia would be welcome. At both $5 \mathrm{~min}$ and $3 \mathrm{~h}$ after reoxygenation, GSE produces better protection when combined with hypothermia, but has significant protection even without hypothermia.

\section{REFERENCES}

1. Buonocore G, Perrone S, Bracci R 2001 Free radicals and brain damage in the newborn. Biol Neonate 79:180-186

2. McCord JM 1985 Oxygen-derived free radicals in post-ischemic tissue injury. N Engl J Med 312:159-163

3. Volpe JJ 2001 Perinatal brain injury: from pathogenesis to neuroprotection. Ment Retard Dev Disabil Res Rev 7:56-64

4. Fine AM 2000 Oligomeric proanthocyanidine complexes: history, structure, and phytopharmaceutical applications. Altern Med Rev 5:144-151

5. Bagchi D, Grarg A, Krohn RL, Bagchi M, Tran MX, Stohs SJ 1997 Oxygen free radical scavenging abilities of Vitamins $\mathrm{C}$ and $\mathrm{E}$, and a grape seed proanthocyanidin extract in vitro. Res Commun Mol Pathol Pharmacol 95:179-190

6. Ariga T 2004 The antioxidant function, preventive action on disease and utilization of proanthocyanidins. Biofactors 21:197-201

7. Devi A, Jolitha AB, Ishii N 2006 Grape seed proanthocyanidin extract (GSPE) and antioxidant defense in the brain of adult rats. Med Sci Monit 12:BR124-BR129.

8. Balu M, Sangeetha P, Murali G, Panneerselvam C 2006 Modulatory role of grape seed extract on age-related oxidative DNA damage in central nervous system of rats. Brain Res Bull 68:469-473

9. Bagchi D, Sen CK, Ray SD, Das DK, Bagchi M, Preuss HG, Vinson JA 2003 Molecular mechanisms of cardioprotection by a novel grape seed proanthocyanidin extract. Mutat Res 523/524:87-97

10. Sato M, Bagchi D, Tosaki A, Das DK 2001 Grape seed proanthocyanidin reduces cardiomyocyte apoptosis by inhibiting ischemia/reperfusion-induced activation of JNK-1 and C-JUN. Free Radic Biol Med 31:729-737

11. Sato M, Maulik G, Ray PS, Bagchi D, Das DK 1999 Cardioprotective effects of grape seed proanthocyanidin against ischemic reperfusion injury. J Mol Cell Cardiol 31:1289-1297

12. Hwang IK, Yoo KY, Kim DS, Jeong YK, Kim JD, Shi HK, Lim SS, Yoo ID, Kang TC, Kim HK, Moon WK, Won MH 2004 Neuroprotective effects of grape seed extract on neuronal injury by inhibiting DNA damage in the gerbil hippocampus after transient forebrain ischemia. Life Sci 75:1989-2001

13. Nakagawa T, Yokozawa T, Satoh A, Kim HY 2005 Attenuation of renal ischemiareperfusion injury by proanthocyanidin-rich extract from grape seeds. J Nutr Sci Vitaminol (Tokyo) 51:283-286

14. Feng Y, Liu YM, Fratkins JD, LeBlanc MH 2005 Grape seed extract suppresses lipid peroxidation and reduces hypoxic ischemic brain injury in neonatal rats. Brain Res Bull 66:120-127

15. Rice JE, Vannucci RC, Brierley JB 1981 The influence of immaturity on hypoxicischemic brain damage in the rat. Ann Neurol 9:131-141

16. Ashwal S, Pearce WJ 2001 Animal models of neonatal stroke. Curr Opin Pediatr 13:506-516

17. McDonald JW, Chen CK, Trescher WH, Johnston MV 1991 The severity of excitotoxic brain injury is dependent on brain temperature in the immature rat Neurosci Lett 126:83-86

18. Yager J, Towfighi J, Vannucci RC 1993 Influence of mild hypothermia on hypoxicischemic brain damage in the immature rat. Pediatr Res 34:525-529

19. Feng Y, LeBlanc MH 2002 Drug-induced hypothermia begun 5 min after injury with a poly(ADP-ribose) polymerase inhibitor reduces hypoxic brain injury in rat pups. Crit Care Med 30:2420-2424

20. Bona E, Johansson BB, Hagberg H 1997 Sensorimotor function and neuropathology five and six weeks after hypoxia-ischemia in seven-day-old rats. Pediatr Res 42:678-683

21. Palmer C, Vannucci RC, Towfighi J 1990 Reduction of perinatal hypoxic-ischemic brain damage with allopurinol. Pediatr Res 27:332-336

22. Andine P, Thordstein M, Kjellmer I, Nordborg C, Thiringer K, Wennberg E, Hagberg H 1990 Evaluation of brain damage in rat model of neonatal hypoxic ischemia. J Neurosci Methods 35:253-260 
23. McDonald JW, Silverstein FS, Johnston MV 1989 Neuroprotective effects of MK-801, TCP, PCP, and CPP against N-methyl-D-aspartate induced neurotoxicity in an in vivo rat model. Brain Res 490:33-40

24. Hoffman SW, Roof RL, Stein DG 1996 A reliable and sensitive enzyme immunoassay method for measuring 8-iso prostaglandin F2 $\alpha$ : A marker for lipid peroxidation after experimental brain injury. J Neurosci Methods 68:133-136

25. Trescher WH, Ishiwa S, Johnston MV 1997 Brief post-hypoxic-ischemic hypothermia markedly delays neonatal brain injury. Brain Dev 19:326-338

26. Roberts LJ, Morrow JD 2000 Measurement of $F(2)$-isoprostanes as an index of oxidative stress in vivo. Free Radic Biol Med 28:505-513

27. Baines CP, Molkentin JD 2005 STRESS signaling pathways that modulate cardiac myocyte apoptosis. J Mol Cell Cardiol 38:47-62
28. Ray SD, Kumar MA, Bagchi D 1999 A novel proanthocyanidin IH636 grape seed extract increases in vivo bcl-xl expression and prevents acetaminophen-induced programmed and unprogrammed cell death in mouse liver. Arch Biochem Biophys 369:42-58

29. Sugisawa A, Inoue S, Umegaki K 2004 Grape seed extract prevents H2O2-induced chromosomal damage in human lymphoblastoid cells. Biol Pharm Bull 27:14591461

30. Shankaran S, Laptook AR, Ehrenkranz RA, Tyson JE, McDonald SA, Donovan EF, Fanaroff AA, Poole WK, Wright LL, Higgins RD, Finer NN, Carlo WA, Duara S, Oh W, Cotton CM, Stevenson DK, Stoll BJ, Lemons JA, Guillet R, Jobe AH 2005 Whole body hypothermia for neonates with hypoxic-ischemic encephalopathy. N Engl J Med 353:1574-1584 